
SUSUNAN DEWAN REDAKSI

“JURNAL NASIONAL KOMPUTASI DAN TEKNOLOGI INFORMASI (JNKTI)"

\author{
Penanggung Jawab \\ Muhammad Fadhli, S.Kom, M.Kom \\ Ketua Dewan Editor \\ Zulfan, ST, MT \\ Editor Pelaksana \\ Munawir, ST, MT \\ Baihaqi, ST, MT \\ Sekretaris \\ Yeni Yanti, ST, MT \\ Mitra Bestari \\ Prof. Dr. Ir. Yuwaldi Away, M.Sc \\ Dr. Taufiq A. Gani, S.Kom, M.Eng.Sc \\ Dr. Melinda, ST, M.Sc \\ Layout \\ Eka Novendra, ST \\ Penerbit \\ Program Studi Teknik Informatika \\ Universitas Serambi Mekkah \\ Alamat Penerbit
}

Gedung H Fakultas Teknik Universitas Serambi Mekkah

Jl. T. Imum Lueng Bata, Telp. (0651)26160 Batoh - Banda Aceh 


\section{SINOPSIS}

Jurnal Nasional Komputasi dan Teknologi Informasi (JNKTI) merupakan jurnal ilmiah nasional yang diterbitkan oleh Program Studi Teknik Informatika Universitas Serambi Mekkah yang mempublikasikan artikel-artikel ilmiah dalam bidang komputasi dan teknologi informasi.Jurnal ini terbit sebanyak 2 (dua) kali dalam 1 (satu) tahun yaitu pada Bulan April dan Oktober. Bidang-bidang fokus penelitian yang akan dipublikasi dalam jurnal ini antara lain :

- Bidang Rekayasa Perangkat Lunak

- Bidang Jaringan Komputer

- Bidang Multimedia dan Pengolahan Citra Digital

- Bidang Komputasi

- Multidisiplin ilmu lainnya yang relevan 
DAFTAR ISI

JNKTI VOL.2 NO.1, APRIL 2019

Studi Simulasi Aerodinamika Airfoil dan Prediksi

$1-8$

Performa Picth Tetap Turbin Angin Poros Tegak (Darrieus)

terhadap Output Power untuk Aplikasi Kecepatan Angin Rendah

Wahyu Priyanto ${ }^{1}$, Ira Devi Sara ${ }^{2}$, Rakhmad Syafutra Lubis ${ }^{3}$

Analisis Performansi Video Streaming Dengan Menggunakan

$9-12$

Protokol RTSP Pada Jaringan IEEE 802.11n

Rahmad Rizki ${ }^{1}$, Rizal Munadi ${ }^{2}$, Syahrial $^{2}$

Pengaruh Heatsink Terhadap Kinerja Modul Surya

$13-18$

T. Mizan Sya'rani D. ${ }^{1 *}$, Ira Devi Sara ${ }^{2}$, dan Laina Hilma Sari ${ }^{3}$

Penentuan Tingkat Penyebaran Ikan Berdasarkan Citra

Suhu Permukaan Laut Di Perairan Laut Kabupaten Aceh Jaya

Menggunakan Satelit Aqua Modis

Naziran ${ }^{1}$, Rizal Munadi ${ }^{2}$, Muchlisin ${ }^{2}$

Studi Pengaruh Hibridisasi Seleksi Roullete Wheel Dengan $26-30$

Tournament Selection Menggunakan Algoritma Berevolusi Pada TSP

Cut lilis Setiawati ${ }^{1}$, Taufiq Abdul Gani ${ }^{2}$, Yuwaldi Away ${ }^{2}$

Audit Dan Optimasi Energi Listrik Pada Bangunan Kampus $31-37$

Menggunakan Metode Algoritma Genetika

Samsuddin $^{1}$, Suriadi ${ }^{2}$, Yuwaldi Away ${ }^{3}$

Aplikasi Histogram Discrete Cosine Transform (DCT) Untuk $38-42$

Sistem Temu Kembali Citra Termal Berbasis Konten

Faridah $^{1}$, Khairul Munadi ${ }^{2}$, Fitri Arnia ${ }^{3}$

Pengujian Algoritma Artificial Neural Network (ANN) $43-47$

Untuk Prediksi Kecepatan Angin

Syukri $^{1}$, Samsuddin ${ }^{2}$

Penerapan Information Retrieval Menggunakan Pemodelan $48-54$

Topik Pada Deskripsi Portal Multimedia

Indra Gita Anugrah ${ }^{1}$ dan Harunur Rosyid ${ }^{2}$

Analisa Steganografi untuk Citra Bewarna (RGB)

Menggunakan Metode Less Significant Bit (LSB)

Raihan Islamadina $^{1}$, Baihaqi $^{2}$, dan Mauzar sulistriadi ${ }^{3}$ 


\title{
Pengujian Algoritma Artificial Neural Network (ANN) Untuk Prediksi Kecepatan Angin
}

\author{
Syukri ${ }^{1}$, Samsuddin ${ }^{2}$ \\ ${ }^{1}$ Program Studi Teknik Informatika, Universitas Jabal Ghafur \\ ${ }^{2}$ Program Studi Teknik Komputer, Universitas Serambi Mekkah \\ ${ }^{1}$ syukrie03@yahoo.co.id
}

\begin{abstract}
Abstrak - Angin memiliki peran yang penting dalam kehidupan manusia, antara lain pada pembangkit listrik, pelayaran dan penerbangan. Ketiga sektor tersebut erat kaitannya dengan kondisi angin. Angin dapat muncul setiap saat dan setiap waktu serta perubahan geografis pada suatu wilayah. Hal ini mengakibatkan sulitnya menentukan kecepatan angin, maka untuk mengatasi masalah tersebut diperlukan prediksi kecepatan angin. Saat ini berbagai metode prediksi telah banyak dikembangkan, salah satu metode yang dapat digunakan untuk melakukan prediksi dengan akurasi yang tinggi yaitu algoritma Artificial Neural Network (ANN) Backpropagation. Arsitektur ANN yang digunakan adalah 4 parameter input layer, hidden layer $(5,10,15,20,25$ dan 30) dan output layer (1 parameter). Data pembelajaran dan pengujian didapatkan dari stasiun BMKG Blang Bintang Aceh Besar, berupa data kecepatan angin jam per harian periode Januari 2011 sampai dengan Desember 2015 yang terdiri dari arah angin, suhu, tekanan, kelembaban dan suhu. Hasil pengujian menunjukkan bahwa metode ANN Backpropagation cukup baik diterapkan untuk proses prediksi, kemampuan ANN dalam melakukan prediksi memiliki tingkat akurasi rata - rata yang lebih baik yaitu $96 \%$. Sedangkan nilai rata - rata kerapatan daya angin jam per harian yaitu $45.030 \mathrm{~W} / \mathrm{m}^{2}$.
\end{abstract}

\section{Kata kunci: Kecepatan angin, Prediksi energi angin, ANN, Backpropagation}

Abstract - The wind has an important role in human life, including power generation, voyage and aviation. The third sector is closely related to the wind condition. The wind can appear at any time and every time and geographical changes in the region. This made it difficult to determine the wind speed, it is necessary to solve the problem of wind speed prediction.Nowadays various prediction methods have been developed. one of the methods that can be used to predict with high accuracy which algorithms Artificial Neural Network (ANN) Backpropagation. ANN used by architecture using four parameters that is input layer, hidden layer $(5,10,15,20,25$ and 30) and the output layer (one parameter). The test results showed that the method of Backpropagation ANN is quite good to be applied on the prediction process, the ability of ANN in conducting predictions hasbetteraverage accuracy at $96 \%$. While the value - average of wind power density of hours per day is about $45030 \mathrm{~W} / \mathrm{m} 2$.

\section{Keywords: wind speed, wind energy predict, ANN, Back propagation}

\section{Pendahuluan}

Kebutuhan akan sumber daya energi alternatif merupakan suatu yang sangat penting untuk perkembangan sosial ekonomi pada suatu daerah. Sumber energi alternatif yang dapat diperbaharui yaitu salah satu angin. Angin yang bertiup pada suatu wilayah memiliki karakteristik kecepatan dan arah tertentu, yang nilainya selalu berubah-ubah setiap waktu sesuai dengan kondisi suhu, tekanan udara dan kelembaban setempat. Pemamfaatan energi angin dengan penggerakkan turbin angin, memerlukan pengetahuan tentang kondisi angin setempat agar kondisi angin dapat diketahui dengan meramalkan kecepatan angin berdasarkan data angin sebelumnya. Ada beberapa metode prediksi kecepatan angin yaitu didtribusi weibull, Rayleigh dan lainnya. Tetapi kebutuhan prediksi yang akurat, maka diperlukan metode yang tepat [1]. Salah satu teknik prediksi yang dikembangkan adalah Artificial Neural Network (ANN) [2]. Metode ini menggunakan elemen perhitungan non-linier dasar yang disebut neuron yang diorganisikan sebagai jaringan yang saling berhubungan antara masukan (input) dan keluaran (output) [3].

Pada penelitian yang dilakukan oleh Budiastra, dkk. [4], belum menggunakan metode prediksi yang tepat untuk kecepatan angin. Penelitian yang dilakukan oleh [5], masih pada proses pengkajian potensi angin dan belum menggunakan metode yang diharapkan. Penelitian yang dilakukan [6], bahwa algoritma backpropagation merupakan algoritma yang terbaik yang dirancang untuk mengurangi kesalahan antara hasil sebenarnya dan hasil yang diinginkan dari jaringan dengan suatu pola teratur.

Berdasarkan uraian tersebut, maka penulis melakukan penelitian tentang akurasi model Artificial Neural Network (ANN) dalam memprediksi kecepatan angin untuk menghasilkan energi listrik dengan menggunakan data time series dan algoritma Backpropagation sebagai proses training sehingga diharapkan dapat memiliki akurasi yang tinggi yaitu dengan rendahnya tingkat error dalam memprediksi besarnya kecepatan angin yang dihasilkan.

Untuk mengetahui keakuratan model ANN backpropagation untuk memprediksi kecepatan angin dengan melihat tingkat error dalam memprediksi besarnya kecepatan angin yang dihasilakan dengan menggunakan algoritma backpropagation sebagai proses training dan didalamnya sebagai proses learning.

Hasil penelitian ini supaya pengguna kecepatan angin untuk menghasilkan listrik dapat menggunakan model 
algoritma Artificial Neural Network (ANN) Backpropagation sebagai alat untuk memprediksi besarnya kecepatan angin pada waktu tertentu guna berapa energi listrik yang dapat dihasilkan dan pengaturan turbin angin dari kecepatan angin dengan akurasi yang tinggi.

\section{Studi Pustaka}

Prediksi adalah salah satu srategi yang digunakan untuk merencanakan pekerjaan sebelum benar - benar terjadi. Banyak jenis prediksi yang dihasilkan, prediksi juga untuk meramalkan masa depan berdasarkan pada masa lalu yang terdiri dari beberapa variabel seperti arah angin, suhu udara, tekanan udara dan kelembaban, atas dasar data masa lalu [7]. ANN adalah sebuah alat pemodelan data statistik non-linier dan dapat digunakan untuk memodelkan hubungan yang kompleks antara input dan output untuk menemukan polapola data [8]. Sistem pemebelajaran merupakan proses penambahan pengetahuan pada ANN yang sifatnya kontinuitas sehingga sehingga pada saat digunakan pengetahuan tersebut akan diekploitasikan secara maksimal dalam mengenali suatu objek [9]. Neuron adalah bagian dasar dari pemrosesan suatu ANN. Dibawah ini bentuk dasar dari suatu neuron.

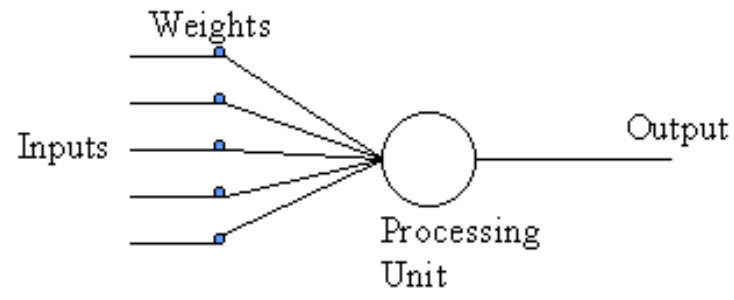

Gambar 1. Bentuk dasar Neuron [10]

Keterangan Gambar 2.1 di atas adalah sebagai berikut:

a. Input merupakan masukan yang digunakan baik saat pembelajaran maupun dalam mengenali suatu objek.

b. Weight, beban yang selalu berubah setiap kali diberikan input sebagai proses pembelajaran.

c. Prosessing unit, tempat berlangsungnya proses pengenalan suatu objek berdasarkan pembebanan yang diberikan.

Arsitektur jaringan dan algoritma pelatihan sangat menentukan model-model ANN. Arsitektur tersebut gunanya untuk menjelaskan arah perjalanan sinyal atau data di dalam jaringan. Sedangkan algoritma belajar menjelaskan bagaimana bobot koneksi harus diubah agar pasangan masukan-keluaran yang diinginkan dapat tercapai [11]. Neuron-neuron tersebut terkumpul di dalam lapisan-lapisan yang disebut neuron layers. Layer-layer penyusun ANN dapat dibagi menjadi 3, yaitu [12-13]:

a. Input layer

Input layer adalah lapisan yang terdiri dari unit-unit (neuron) input yang langsung menerima sinyal input dari luar dan mengirim informasi input yang diterima ke setiap neuron yang ada pada hidden layer melalui bobot yang menghubungkan lapisan input dan lapisan tersembunyi.

b. Hidden layer
Hidden layer adalah lapisan yang terdiri dari unit-unit (neuron) tersembunyi yang terletak antara input layer dan output layer diman outputnya tidak secara langsung diamati. Penambahan hidden layer ini dapat meningkatkan kemampuan jaringan dalam pengenalan pola.

c. Output layer

Output layer adalah lapisan yang terdiri dari unit-unit output dimana keluaran dari lapisan output merupakan solusi ANN pada suatu masalah.

Terdapat beberapa fungsi aktifasi , antara lain sigmoid biner, sigmoid bipolar, hiperbolik dan lain sebagainya. Penelitian ini akan menggunakan fungsi aktifasi sigmoid biner yang mana dapat dilihat persamaan 1 berikut:

$$
f_{1}(x)=\frac{1}{1+x^{-x}}
$$

Dalam proses pelatihan backpropagation terdapat tiga tahap yaitu [2],[11],[14]:

a. Tahap maju

Pada tahap ini seluruh proses awal inisialisasi bobotbobot input dilakukan.

b. Tahap mundur

Pada tahap ini, nilai error $\left(\delta_{k}\right)$ yang diperoleh pada lapisan output digunakan untuk mengoreksi bobot-bobot yang ada pada lapisan tersembunyi yang berhubungan langsung dengan lapisan output.

c. Tahap pengoreksian bobot

Setelah seluruh bobot pada lapisan input dan lapisan tersembunyi dimodifikasi sesuai dengan besar faktor errornya, maka ketiga fase ini diulang secara terus menerus sampai kondisi berhenti dipenuhi.

Struktur pelatihan algoritma Backpropagation adalah :

a. Iniasilasi bobot-bobot

Tentukan angka pembelajaran dan nilai toleransi error yang diinginkan dan set maksimal epoch jika ingin membatasi nilai epoch yang digunakan.

b. Jika kondisi tidak tercapai, lakukan langkah 2-9.

c. Untuk setiap pola pasangan pelatihan, lakukan langkah 3-8.

1. Tahap maju

a. Tiap-tiap unit input $\left(\mathrm{x}_{\mathrm{i}}, \mathrm{i}=1,2,3, \ldots \mathrm{n}\right)$ menerima sinyal input dan meneruskan ke semua unit tersembunyi.

b. Tiap-tiap unit dilapisan tersembunyi $\left(\mathrm{z}_{\mathrm{j}, \mathrm{j}} \mathrm{j}=1,2,3, \ldots, \mathrm{p}\right)$ menjumlahkan sinyal-sinyal input yang berbobot,

$$
\mathrm{z} \_n e t_{\mathrm{j}}=\mathrm{v}_{\mathrm{j} 0}+\sum_{i=1}^{n} x_{1} v_{j i}
$$

fungsi aktivasi menghitung sinyal outputnya,

$$
\mathrm{z}_{\mathrm{j}}=\mathrm{v}_{\mathrm{j} 0}+\sum_{i=1}^{n} x_{1} v_{j i}
$$

dan mengirimkan sinyal tersebut ke semua unit pada lapisan output.

c. Tiap-tiap unit pada lapisan output $\left(\mathrm{y}_{\mathrm{k}}, \mathrm{k}=1,2,3, \quad \ldots\right.$, $\mathrm{m})$ menjumlahkan sinyal input yang berbobot,

$$
\mathrm{y} \_n e t_{\mathrm{k}}=\mathrm{w}_{\mathrm{k} 0}+\sum_{j=1}^{p} z_{j} w_{k j}
$$


Fungsi aktifasi untuk menghitung sinyal output,

$$
\mathrm{y}_{\mathrm{k}}=\mathrm{w}_{\mathrm{k} 0}+\sum_{j=1}^{p} z_{j} w_{k j}
$$

2. Tahap mundur

a. Tiap-tiap unit output $\mathrm{y}_{\mathrm{k}}$ menerima pola menerima pola target $\mathrm{t}_{\mathrm{k}}$ untuk menghitung error $\left(\delta_{k}\right)$,

$$
\delta_{k}=\left(t_{k}-y_{k}\right) f^{\prime}\left(y_{-} n e t_{k}\right)=\left(t_{k}-y_{k}\right) y_{k}\left(1-y_{k}\right)
$$

hitung koreksi bobotnya untuk memperbaiki nilai bobot antara lapisan tersembunyi dan lapisan output $\left(\mathrm{w}_{\mathrm{jk}}\right)$,

$$
\Delta w_{j k}=\alpha \delta_{k} z_{j}
$$

Hitung koreksi bias digunakan untuk memperbaiki nilai bias antara lapisan tersembunyi dan lapisan output $\left(\mathrm{w}_{\mathrm{ko}}\right)$,

$$
\Delta w_{k 0}=\alpha \delta_{k}
$$

b. Tiap-tiap unit lapisan tersembunyi $\left(z_{j}, j=1,2,3, \ldots, p\right)$ menjumlahkan sinyal-sinyal input dari lapisan output,

$$
\delta_{-} n e t_{j}=\sum_{k=1}^{m} \delta_{k} w_{j k}
$$

Kalikan dengan fungsi aktifasi untuk menghitung error pada lapisan tersembunyi $\left(\delta_{j}\right)$,

$$
\delta_{j}=\delta_{-} n e t_{j} f^{\prime}\left(z_{-} n e t_{j}\right)=\delta_{-} \text {net }_{j} z_{j}\left(1-z_{j}\right)
$$

Hitung koreksi bobot untuk memperbaiki nilai bobot antara lapisan input dan lapisan tersembunyi $\left(\mathrm{v}_{\mathrm{ji}}\right)$,

$$
\Delta v_{j i}=\alpha \delta_{j} x_{i}
$$

Hitung koreksi bias untuk memperbaiki nilai bobot antara lapisan input dan lapisan tersembunyi $\left(\mathrm{v}_{\mathrm{jo}}\right)$,

$$
\Delta v_{j 0}=\alpha \delta_{j}
$$

3. Tahap pengoreksi bobot

c. Tiap-tiap unit keluaran $\left(\mathrm{y}_{\mathrm{k}}, \mathrm{k}=1,2,3, \ldots, \mathrm{m}\right)$ memperbaiki bobot dan bias,

$$
\begin{gathered}
w_{k j}(\text { baru })=w_{k j}(\operatorname{lama})+\Delta w_{k j}, \\
(k=1,2, \ldots, m ; j=0,1, \ldots, p)
\end{gathered}
$$

tiap-tiap unit tersembunyi bobot dan bias,

$$
\begin{gathered}
v_{j i}(\text { baru })=v_{j i}(\text { lama })+\Delta v_{j i}, \\
(j=1,2, \ldots, p ; i=0,1, \ldots, n)
\end{gathered}
$$

d. Tes kondisi berhenti.

\section{Metode Penelitian}

Pada penelitian ini, data yang digunakan adalah data kecepatan angin jam per hari Tahun 2011 sampai dengan Tahun 2015 yang diperoleh dari stasiun BMKG Blang Bintang Aceh Besar. Data yang digunakan adalah kecepatan angin, arah angin, suhu udara, tekanan udara dan kelembaban serta dikelompokkan menjadi dua yaitu data pembelajaran dan pengujian.

Data pembelajaran dan pengujian akan dinormalisasi agar berada pada range $[0.1,0.9]$. Berdasarkan penjelasan mengenai algoritma ANN Backpropagation, proses penentuan jaringan arsitektur ANN yang dibangun pada penelitian ini dapat dilihat pada gambar 3.1 dimana y adalah hasil prediksi potensi angin.

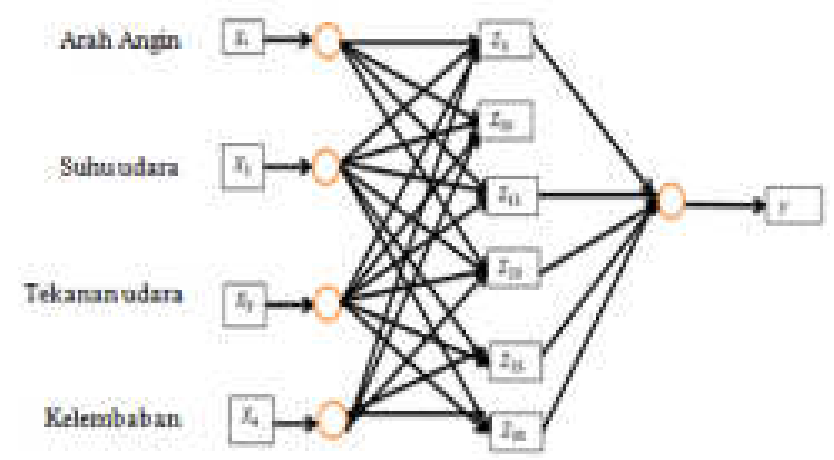

Gambar 2. Arsitektur Artificial Neural Network

Dari gambar 3.1 diperlihat jaringan dengan empat buah unit masukan $\left(\mathrm{X}_{1}, \mathrm{X}_{2}, \mathrm{X}_{3}, \mathrm{X}_{4}\right)$, sebuah hidden layer yang terdiri atas 5 sampai dengan 30 neuron $\left(Z_{5}, Z_{10}, Z_{15}, Z_{20}, Z_{25}\right.$, $\mathrm{Z}_{30}$ ), dan sebuah unit keluaran $\left(Y_{1}\right)$. 


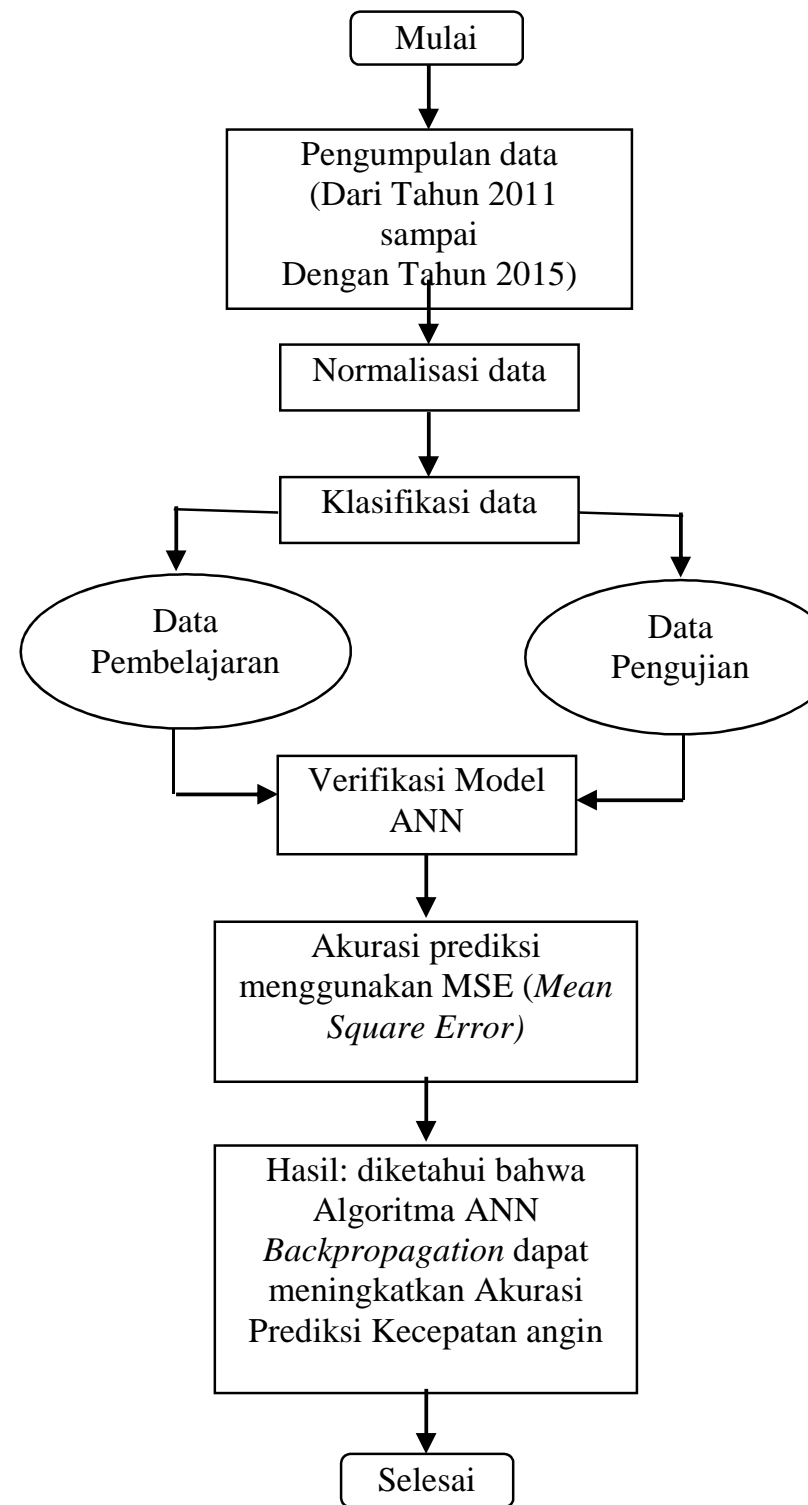

Gambar 3. Tahapan Penelitian

Langkah untuk merancang ANN Backpropagation yaitu pengumpulan data yang akan dijadikan variabel masukan (input) dan target yang menjadi keluarannya (output). Berdasarkan penjelasan dari algoritma ANN Backpropagation, proses penentuan bentuk arsitektur ANN yang dibangun pada penelitian ini diperlihatkan pada gambar 3 .

Untuk mencapai tujuan, maka penulis melakukan beberapa tahapan penelitian. Tahapan pertama mengumpulkan data, normalisasi data, klasifikasi data (data pembelajaran dan pengujian), membangun jaringan ANN, verifikasi model ANN, akurasi prediksi menggunakan MSE dan hasil menjalankan seperti gambar 3 .

Adapun Proses pengujian model algoritma ANN untuk memprediksi potensi energi angin dapat dilihat pada diagram alir berikut:

\section{Hasil dan Pembahasan}

Hasil penerapan algoritma ANN Backpropagation pengujian model Artificial Neural Network (ANN) berbasis algoritma backpropagation untuk mengetahui prediksi potensi energi angin dengan menggunakan data kecepatan angin dari BMKG Blang Bintang Aceh Besar. Maka didapatkan hasil bahwa algoritma ANN Backpropagation mampu memprediksi keakuratan potensi energi angin dan dapat digunakan untuk pengembangan pembangkit tenaga angin. memprediksikan kecepatan angin adalah sebagai berikut:

\subsection{Normalisasi}

Contoh hasil normalisasi data kecepatan angin dapat dilihat pada table 1 di bawah ini:

Tabel 1. Hasil normalisasi data kecepatan angin 1Januari 2015 dari jam 00.00 wib sampai dengan jam 23.00 wib.

\begin{tabular}{|c|c|c|c|}
\hline Jam & Normalisasi data & Jam & Normalisasi data \\
\hline 00.00 & 0.000 & 12.00 & 0.000 \\
\hline 00.01 & 0.571 & 13.00 & 0.143 \\
\hline 00.02 & 0.357 & 14.00 & 0.786 \\
\hline 00.03 & 0.214 & 15.00 & 0.143 \\
\hline 00.04 & 0.786 & 16.00 & 0.571 \\
\hline 00.05 & 0.000 & 17.00 & 1.000 \\
\hline 00.06 & 0.286 & 18.00 & 0.000 \\
\hline 00.07 & 0.000 & 19.00 & 0.357 \\
\hline 00.08 & 0.000 & 20.00 & 0.286 \\
\hline 00.09 & 0.071 & 21.00 & 0.000 \\
\hline 10.00 & 0.143 & 22.00 & 0.286 \\
\hline 11.00 & 0.500 & 23.00 & 0.429 \\
\hline
\end{tabular}

\subsection{Hasil pengujian Model ANN dengan MSE}

Dari hasil proses pembelajaran dan pengujian yang dilakukan, maka hasil prediksi terbaik untuk setiap tahunnya tidak selalu dengan menggunakan data dua bulan (pada tahun 2015). Hal ini menunjukkan bahwa karakteristik data pembelajaran sangat menentukan hasil pengujian, walaupun dengan menggunakan data satu bulan, tiga bulan, empat bulan, lima bulan dan satu tahun, ketika karakteristik data pembelajarannya mampu mewakili karakteristik data pengujian, maka hasil prediksi akan menghasilkan mse terkecil. Maka output model yang digunakan untuk prediksi potensi energi angin yaitu hasil terbaik (memiliki nilai mse terkecil) dengan menggunakan data dua bulan (januari dan maret) pada tahun 2015. Nilai error terkecil pada setiap tahunnya dapat dilihat pada tabel 2 dibawah ini

Tabel 2. Hasil proses error pembelajaran dan error pengujiann ANN Backpropagation prediksi kecepatan angin

\begin{tabular}{|c|c|c|c|}
\hline Jumlah data & Neuron & $\begin{array}{c}\text { MSE } \\
\text { Pembelajaran }\end{array}$ & $\begin{array}{c}\text { MSE } \\
\text { Pengujian }\end{array}$ \\
\hline 1 bulan & 20 & 0.00136 & 0.00126 \\
\hline 2 bulan & $\mathbf{2 0}$ & $\mathbf{0 . 0 0 1 3 2}$ & $\mathbf{0 . 0 0 1 2 1}$ \\
\hline 3 bulan & 20 & 0.00774 & 0.00857 \\
\hline 4 bulan & 20 & 0.00381 & 0.00123 \\
\hline 5 bulan & 15 & 0.00432 & 0.00128 \\
\hline
\end{tabular}




\begin{tabular}{|c|c|c|c|}
\hline 6 bulan (1) & 30 & 0.00323 & 0.00194 \\
\hline 2 Tahun & 30 & 0.00581 & 0.00321 \\
\hline 3 Tahun & 25 & 0.00149 & 0.00274 \\
\hline 4 Tahun & 10 & 0.00215 & 0.0036 \\
\hline 5 Tahun & 30 & 0.0017 & 0.00538 \\
\hline
\end{tabular}

Berdasarkan tabel 4.2 dapat diketahui bahwa nilai error terkecil didapatkan pada data dua bulan (Januari dan Maret 2015). Semakin banyak data latih tidak menunjukkan semakin kecil nilai errornya. Dari proses pembelajaran ANN Backpropagation dengan menggunakan data satu bulan sampai dengan data lima tahun menghasilkan nilai error paling kecil pada dua bulan dengan mse pembelajaran yaitu 0.00132 dan mse pengujian yaitu 0.00121 .

\subsection{Hasil Prediksi Kecepatan Dengan Model Dua Bulan}

\section{Tahun 2015}

Hasil prediksi potensi angin dengan menggunakan data input/output satu bulan sampai lima tahun, maka diperoleh hasil terbaik pembelajaran dan pengujian pada dua bulan (data bulan Januari dan bulan Maret 2015). Hasil prediksi kecepatan angin dengan metode ANN Backpropagation menggunakan data dua bulan, pengujian MSE dan tingkat akurasi menunjukkan bahwa sistem pelatihan ANN Backpropagation dapat digunakan untuk prediksi kecepatan angin. Hal ini ditunjukkan oleh nilai MSE yang dihasilkan sebesar 0.00990 dan akurasi $99 \%$. Dapat dilihat pada tabel berikut.

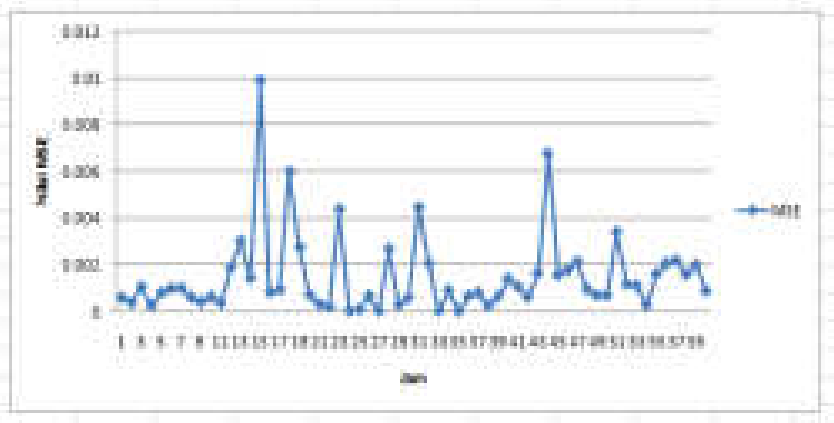

Gambar 4. Nilai MSE dan waktu

Berdasarkan tabel 4.3 di atas diketahui bahwa pengujian terhadap MSE dan tingkat akurasi menunjukkan bahwa sistem pelatihan Algoritma ANN dengan backpropagation dapat digunakan untuk memprediksi kecepatan angin. Hal ini ditunjukkan dengan tingkat akurasi maksimum yaitu 99\%, Secara grafis perbedaan nilai mean square error ditunjukkan pada gambar 4.1 di bawah ini.

\subsection{Hasil prediksi potensi angin di lokasi terpilih}

Kecepatan angin pada lokasi terpilih diprediksikan dengan menggunakan model ANN yang memiliki arsitektur hidden layer 20 neuron pada dua bulan (Januari dan Maret 2015) dengan MSE yang paling kecil. Kerapatan daya angin yang dihasilkan dengan menggunakan data kecepatan angin pada tanggal 1 januari 2015 pada hari kamis dapat dilihat pada gambar 5 .

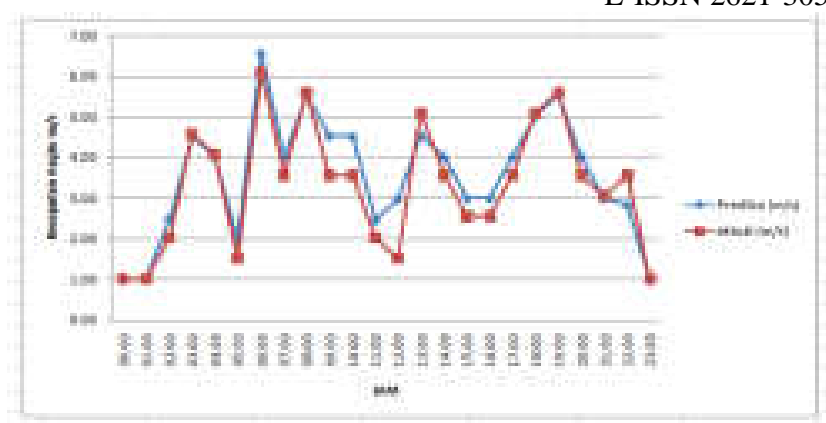

Gambar 5. Hasil prediksi kec. Angin berdasarkan di lokasi terpilih pada tanggal 1 januari 2015

Berdasarkan tabel 4.4 di atas diketahui bahwa massa jenis angin yaitu $1.225 \mathrm{~kg} / \mathrm{m}^{3}$ maka kerapatan daya angin harian tanggal 1 januari 2016 nilai maksimum terbesar ditunjukkan pada jam 06.00 Wib sebesar $1308.814 \mathrm{~W} / \mathrm{m}^{2}$ dan nilai minimum ditunjukkan pada jam $23.00 \mathrm{Wib}$ sebesar $4.361 \mathrm{~W} / \mathrm{m}^{2}$. Sedangkan nilai rata-rata kerapatan daya angin pada harian sebesar $339.461 \mathrm{~W} / \mathrm{m}^{2}$. Namun besarnya kerapatan daya angin sangat tergantung pada kecepatan angin, makin besar potensi angin maka makin besar kerapatan daya angin.

\section{Kesimpulan}

Berdasarkan hasil penelitian dan pembahasan mengenai pengujian algoritma ANN backpropagation untuk memprediksi potensi energi angin, maka dalam bab ini peneliti akan mengambil kesimpulan sebagai berikut:

1. Kecepatan angin rata-rata harian sebesar $3.99 \mathrm{~m} / \mathrm{s}$ untuk lokasi terpilih berdasarkan pembelajaran dan pengujian ANN backpropagation, model ini mampu menghasilkan nilai keakuratan sebesar $99 \%$ dalam memprediksi kecepatan angin. Hal ini dibuktikan dari hasil proses pelatihan sejumlah data dari satu bulan sampai dengan lima tahun, diperoleh nilai error terkecil dengan menggunakan data dua bulan pada tahun 2015 .

2. Nilai potensi angin pada lokasi terpilih dengan kecepatan angin rata-rata sebesar $3.99 \mathrm{~m} / \mathrm{s}$ pada ketinggian 10 meter, maka sudah dapat untuk pembangunan pembangkit tenaga angin.

\section{Daftar Pustaka}

[1]. S. Kalogirou, C. Neocleous, S. Pashiardis, C. Schidas, and P. O. Box, "Wind Speed Prediction Using Artificial Neural Network *Ministry of Agriculture, Natural Resources and Enviroment," University of Cyprus Departement of Computer Sciene." University of Cyprus . 2010.

[2]. A. Purnama, "Peramalan Kecepatan Angin Jang Pendek Untuk Pembangkit Listrik Tenaga Bayu Menggunakan Saraf Jaringan Tiruan Propagasi Balik," Tesis, UI., Depok, Indonesia, 2011.

[3]. P.P.Kadu, K.P.Wagh and P.N.Chatur, "Temperature Prediction System using Backpropagation Neural Network," An Approach Internasional Jurnal of Computer Science and Comunication, Networks, II (1), pp.61-64. 2012. 
